\title{
Tierra de propiedad social, turismo y expansión urbana en San José del Cabo, Baja California Sur (México)
}

\author{
Jesús Bojorquez Luque* \\ Universidad Autónoma de Baja California Sur (Mexico)
}

\begin{abstract}
Resumen: Los destinos turísticos de Sol y Playa de nueva creación en México, llamados Centros Integralmente Planeados (CIPs) por el Fondo Nacional de Fomento al Turismo (FONATUR), fueron creados en zonas poco desarrollas con excepcionales características paisajísticas, con presencia de núcleos ejidales a los cuales se les expropió una gran cantidad de superficie para materializar dichos polos de desarrollo turístico. Dicha actividad provocó fenómenos de inmigración que derivó en una presión sobre el suelo urbanizable por la población trabajadora recién aposentada. El objetivo del presente trabajo es analizar la aportación del ejido San Jose del Cabo en la creación del CIP Los Cabos, así mismo, a la expansión de la ciudad del mismo nombre. La metodología utilizada fue de carácter cualitativa, basándose en investigación documental a través de consultas al Diario Oficial de la Federación, archivos del Registro Agrario Nacional y reportes de la prensa local.
\end{abstract}

Palabras Clave: Ejido; Turismo; Ciudad; inmigración; Expansión urbana; San José del Cabo

Land of social property, tourism and urban expansion in San Jose del Cabo, Baja California Sur (Mexico).

Abstract: The newly created sun and sand tourist resorts in Mexico, called Integrally Planned Centers (CIP) by the National Tourism Promotion Fund (FONATUR), were created in underdeveloped areas with exceptional landscape features, and with the presence of large estates (ejidos) that had parts expropriated to devote to the new developments. This activity attracted an influx of immigrant workers that produced enormous pressure on the land available for development. The aim of this piece of research is to analyse the contribution made by the San José estate toward the creation of the Los Cabos CIP, as well as to the expansion of the city of the same name. The methodology used was of a qualitative nature, based on the evaluation of documentary research through consultations to the Diario Oficial de la Federación, the archives of the Registro Nacional Agrario and local press.

Keywords: Ejido (Estate); Tourism; City; immigration; Urban expansion; San José del Cabo.

\section{Introducción}

El desarrollo turístico en México se institucionalizó a partir del gobierno de Miguel Alemán Valdés (1946-1952) apuntalando a Acapulco como el destino emblemático de México. Después de Acapulco otros puertos mexicanos, aparte de la actividad portuaria comercial, orientaron esfuerzos en materia turística como Mazatlán, Puerto Vallarta, Veracruz, entre otros, los cuales en la actualidad son considerados destinos tradicionales de playa. En la década de los años setenta la política de Estado en materia turística da un giro y pone a la actividad del ocio en las estrategias de desarrollo prioritarias, para ello se crea en 1974 el Fondo Nacional de Fomento al Turismo (FONATUR) a partir de la Ley de Fomento al Turismo (DOF, 1974) como un fideicomiso (que se encargó de edificar proyectos turísticos como los llamados Centros Integralmente Planeados (CIP) como Cancún, Ixtapa, Loreto, Los Cabos, Nayarit y Playa Espíritu en Sinaloa.

Universidad Autónoma de Baja California Sur (Mexico); E-mail: jesbojorquez70@hotmail.com; https://orcid.org/0000-0002$-1745-4979$ 
Las ciudades en México tuvieron un obstáculo legal en su crecimiento físico, pues estaban cercanas a núcleos ejidales y la Ley de la Reforma Agraria previa a 1992 estipulaba que las tierras ejidales eran inalienables e inembargables, por lo que no se podían enajenar y destinarlas para usos distintos que no sean los agropecuarios. Así, las tierras de origen social eran incompatibles para el desarrollo urbano, de ahí que muchos asentamientos de las ciudades surgieron en la ilegalidad (Bojórquez Luque, 2013), por lo que el Estado mexicano creó mecanismos para su legalización a partir de expropiar las zonas invadidas por fines de utilidad pública y edificó organismos como la Comisión Reguladora de la Tenencia de la Tierra (CORETT) ${ }^{1}$ para la regularización y posterior titulación de los lotes ocupados por la población. De la misma manera, el gobierno federal legalizó superficies para la creación de infraestructura carretera, eléctrica, presas y proyectos turísticos como el que se expone en este trabajo.

En el tenor del impulso de nuevos centros turísticos como los CIP, su materialización se dio en zonas de prístina belleza donde estaba presente la propiedad ejidal, por lo que la federación expropió superficies considerables a los ejidos para la obtención los polígonos donde se desarrollaron los polos turísticos, pero además, en los años posteriores los núcleos agrarios sirvieron como una válvula de escape ante la llegada de inmigrantes que llegaron a dichos destinos atraídos por los empleos ofertados por esa actividad dinamizadora. Con ello, el ejido funcionó como agente que subsidió el desarrollo turístico ante los salarios insuficientes que pagaban las cadenas hoteleras y empresas ligadas al sector turístico para que los trabajadores accedieran al mercado formal de vivienda, por lo que la tierra de propiedad social ayudó a evitar la explosividad social originada por la falta de suelo urbanizable.

En el presente trabajo se analiza el caso de la ciudad de San José del Cabo, Baja California Sur que fue destinatario de las políticas públicas del Estado mexicano con la creación del CIP-Los Cabos, el cual en sus inicios contaba con un pueblo aledaño que se había fundado desde la época colonial, pero que estaba rodeado del ejido del mismo nombre y que fue impactado para la materialización del CIP y como proveedor hasta la actualidad de suelo para una población que creció a altas tasas desde los años ochenta.

El trabajo inicia con un análisis de como el turismo como actividad económica de gran dinamismo, genera inmigración y que al momento de instalarse en las localidades receptoras es partícipe del crecimiento físico de las ciudades. Después se aborda la relación ciudad y ejido a partir de la expansión urbana de las ciudades y la invasión de esta en zonas de núcleos agrarios, surgiendo asentamientos ilegales cuyo rasgo característico es la precarización por falta de servicios públicos. Posteriormente se analiza el surgimiento de los CIPs y como participaron los ejidos en la configuración territorial en los polígonos fundacionales. Utilizando metodología cualitativa en base a investigación documental, por último, se hace una caracterización de la localidad de San José del Cabo y la aportación del ejido en la expansión de la ciudad a partir de los datos del Registro Agrario Nacional (RAN) ${ }^{2}$, del Diario Oficial de la Federación (DOF) y por último de reportes de la prensa para los actuales asentamientos irregulares existentes.

\section{Marco teórico}

\subsection{Turismo y expansión urbana}

Cuando se presenta en cierta región o en alguna localidad una actividad dinamizadora, no sólo hay una generación de riqueza y por consiguiente empleo, sino que hay una fuerza gravitacional para población de otras latitudes que llegan con el objetivo de emplearse y mejorar sus condiciones de vida, convirtiéndose dichos núcleos poblacionales atractivos para la inmigración (Romero, Caballero y Pérez, 2017: 552), resultando no sólo la demanda de vivienda de alquiler, sino suelo urbanizable para instalarse de manera definitiva. El crecimiento acelerado que provocan los polos de desarrollo turístico, genera una serie de externalidades negativas como problemas ambientales al rebasarse los límites de tolerancia en la capacidad de carga de las localidades (Picornell, 1993); elevación en los índices de inseguridad a partir de la drogadicción, alcoholismo, turismo sexual, etc. (Hernández, 2018), entre otros, provocado por la falta de planeación o porque los intentos de planeación son rebasados por los recursos limitados por las autoridades locales para atender las zonas donde se establecen los trabajadores de los complejos hoteleros, las consideradas partes traseras (González, 2013) donde hacen falta la implementación de políticas públicas que atemperen o reduzcan estas problemáticas.

La actividad del ocio centrado en las zonas litorales ha tenido un gran crecimiento en las últimas décadas, donde el capital financiero ha entrado en escena para financiar proyectos de especulación inmobiliaria y edificación de grandes resorts en los llamados destinos de Sol y Playa propiciando una 
tendencia territorial de segregación espacial, donde se separan a los residentes de altos ingresos y turistas (Romero, Del Caño y Romero, 2014: 67), con los asentamientos dormitorios de la clase trabajadora que llega masivamente atraídos por los empleos, que viven en condiciones de déficit de infraestructura urbana y de servicios en salud, educativos y recreativos.

Por lo tanto, el turismo como actividad económica impuesta desde el Estado como forma de dinamizar regiones o localidades en países en subdesarrollo conlleva un gran costo social, que se traduce en efectos urbanos perniciosos a partir de su crecimiento acelerado, manifestando la precarización de la mayoría de los nuevos residentes, asentamientos informales derivado del aumento constante en los precios del suelo, incapacidad de los órdenes de gobierno para proporcionar mínimos de bienestar a la creciente población (Bojórquez Luque, 2014: 346), por lo que el tejido social tiende a dañarse de manera paulatina.

Ejemplos de la problemática urbana en los destinos turísticos originada por su acelerada expansión han sido documentados en la producción académica. Como el caso de Cabo San Lucas, México, donde la actividad turística ha provocado un crecimiento acelerado de la población, llevándose a cabo un despojo paulatino de la propiedad ejidal (Bojórquez y Ángeles, 2014); o como en el destino maduro de Platja de Palma se presentan síntomas de vulnerabilidad y exclusión social (Amer, 2011); la precariedad urbana que genera el turismo en las Islas Baleares (González, 2015); el caso de San Carlos Bariloche en Argentina, están recibiendo mayor cantidad de población inmigrante que otras de similar tamaño, pero con otro tipo de actividades económicas, esto derivado de sus atractivos naturales, además de los empleos asociados a la actividad, dándose una presión sobre el suelo, con su consecuente especulación y encarecimiento (Rodríguez, 2015); los problemas originados por la falta de espacios públicos en la perla del turismo litoral mexicano de Cancún (Sosa y Cazal, 2015); el proceso de gentrificación en Purmamarca, Jujuy, Argentina que ha generado expulsión de población y conflictividad social (Ávalos, 2017). En fin, los ejemplos son extensos, y en el caso de San José del Cabo, nuestra localidad de estudio, el crecimiento de la población ha sido muy elevada, con altas tasas, que trajo como consecuencia el surgimiento de asentamientos irregulares que entraron a un proceso de legalización por parte del Estado mexicano, mayores índices de inseguridad, marginación y precarización debido a grandes rezagos en infraestructura urbana.

\subsection{Ciudad y ejido en México}

La Ley de la Reforma Agraria, producto de la Revolución Mexicana y derivada del artículo 27 constitucional, tenía candados en términos de su uso y destino, los sujetos agrarios no eran dueños de la tierra, sólo tenían los derechos agrarios para explotar las tierras en términos de su vocación agropecuaria, por lo que el Estado era el dueño soberano de las tierras ejidales y comunales. Las tierras de propiedad social eran por tanto inalienables, inembargables e imprescriptibles, por lo cual no podían entrar a la lógica del mercado, entre ello, a destinarla para fines urbanos. Las distintas formas de propiedad de la tierra en nuestro país generaron tensión con la realidad de una urbanización acelerada donde las ciudades tendían a devorar núcleos agrarios a partir de su lógica expansiva y ponían en riesgo el continuo urbano abonando a la falta de planificación. Al margen de los procesos de despojo en los ejidos ante la presión de población demandante de suelo urbanizable, el crecimiento de las ciudades se dio en la mayoría de los casos por invasiones, creándose asentamientos irregulares debido a su condición ejidal, que dificultó la introducción de servicios básicos e infraestructura urbana (Bojórquez Luque, 2011: 297).

Previo a las reformas al 27 constitucional de 1992, la propiedad social de la tierra en el país representó alrededor del 52\% de la nación, con aproximadamente 31 mil núcleos agrarios (Rivera, 2011: 103), por lo tanto, las ciudades estaban copadas por comunidades agrarias. El gobierno del presidente Carlos Salinas de Gortari (1988-2014) impulsó una serie de reformas tendientes a fortalecer el modelo económico neoliberal, entre ellas una reforma al 27 constitucional en 1992 con el argumento de que ya no había más tierra a repartir a comunidades y campesinos, por lo que se anunciaba el fin del reparto agrario y se daba certidumbre jurídica a los sujetos agrarios dándoles títulos de propiedad, iniciando un proceso de privatización de los ejidos y la propiedad comunal. Dichas reformas favorecieron la incorporación de la tierra al mercado formal de tierras, donde constructores e inmobiliarias entraron de lleno a la especulación del suelo ejidal para fines urbanos, sin embargo, dichos cambios no solucionaron del todo las invasiones de colonos a tierras ejidales derivado del encarecimiento de estas en muchas ciudades mexicanas, sobre todo en destinos turísticos de gran crecimiento como lo es San José del Cabo.

En ese tenor de la apropiación ilegal de tierras de los núcleos agrarios, las autoridades crearon mecanismos de regularización a través de expropiaciones con fines de utilidad pública tanto para legalizar asentamientos como para la edificación de infraestructura, equipamiento y vivienda interviniendo 
instituciones creadas para tales fines como la CORETT y del RAN que implementó el Programa de Certificación de Derechos Ejidales y Titulación de Solares (PROCEDE) para la obtención del dominio pleno de los ejidatarios de sus parcelas para que puedan comercializarlas en el mercado formal de suelo (Jiménez y Ayala: 2015: 103).

Las reformas al 27 tuvieron una gran importancia para el presente y futuro de las ciudades mexicanas desde hace 26 años, pues propició condiciones para que el suelo de origen social pudiera incorporarse a usos urbanos, con lo que los gobiernos se les facilitó adquirir reservas territoriales para sectores vulnerables de la población que no estuvieran con la capacidad económica para adquirirla a través de inmobiliarias o fraccionadores privados y ello contribuyera a una mejor planeación en el crecimiento de las ciudades (Olivera, 2015: 161), con este cambio al andamiaje constitucional se hizo normal el acceso a suelo urbano a través de transacciones de compra venta de tierras ejidales en el mercado formal (Pola, Méndez y Vieyra, 2007: 432), aunque persisten todavía invasiones, estas han bajado de manera significativa

\subsection{Los CIP y la propiedad ejidal}

Los destinos turísticos de nuevo cuño impulsados por FONATUR se edificaron en su mayoría en zonas con núcleos ejidales por lo que el gobierno federal impulsó expropiaciones con fines de utilidad pública para obtener los polígonos con superficie suficiente para planificar los polos de desarrollo turístico (Castro, 2007), después de eso se expropiaron superficies a los ejidos para regularizar asentamientos de trabajadores que laboran en los complejos turísticos. En cuanto a la obtención de superficies ejidales para la materialización de los CIP, dichos casos se presentaron en Cancún, Ixtapa, Loreto, Los Cabos, Nayarit, excepto Playa Espíritu, CIP ubicado en Sinaloa, cuyas tierras FONATUR las compró al ex gobernador Antonio Toledo Corro (Inda y Santamaría, 2015: 43; Del Castillo, 20014).

Para la obtención del polígono del CIP de Cancún, FONATUR echó mano de 2.000 hectáreas propiedad de la nación, las cuales fueron aportadas por el gobierno federal; se expropiaron 5.000 hectáreas al ejido Islas Mujeres y las 5.700 restantes se obtuvieron de particulares con los cuales fueron negociadas y adquiridas por el Banco de México (Aldape, 2010: 41). En el caso del CIP de Cancún, el crecimiento acelerado de la población demandó una gran cantidad de tierra urbanizable pues en el municipio de Benito Juárez donde se encuentra Cancún, se establecieron en los años ochenta 13.957 habitantes al año y en el primer lustro del siglo XXI se instalaron 30.631 habitantes por año. Mucha de esa población se estableció al norte de la ciudad, los cuales invadieron un aproximado de 1.300 hectáreas del ejido Isla Mujeres los cuales fueron expropiados por el gobierno para regularizarlos (Aldape, 2010: 29).

En el caso del CIP de Huatulco ubicado en el estado de Oaxaca, se afectó al ejido Santa María de Huatulco con una superficie de 20.974 hectáreas al ejido Santa María Huatulco, de 51.511 que FONATUR necesitó para la edificación del CIP (Talledos, 2012: 128; DOF, 1984). Por su parte en Ixtapa, la federación expropió una serie de ejidos para obtener las tierras necesarias para el polo de desarrollo turístico. Dichos ejidos fueron Agua de Correa, Zihuatanejo y El Rincón. Para la administración del proyecto, en 1974 se creó el Fideicomiso de la Bahía de Zihuatanejo (FIBAZI) quien se encargó de urbanizar el desarrollo turístico y también de indemnizar a cada uno de los ejidatarios (Gómez, 2015). Del ejido Agua de Correa del municipio de José Azueta, se expropiaron una superficie de un poco más de 813 has (DOF, 1973a); al ejido El Rincón, municipio de José Azueta, se expropió una superficie de 206 has (DOF, 1973b); y por último al ejido Zihuatanejo, municipio de José Azueta, una superficie expropiada de 480 has (DOF, 1973c).

Para la obtención de las tierras del CIP Loreto, el " $24 \%$ era el casco antiguo de la localidad, 34,4\% de la nueva zona urbana; las 16\% áreas de conservación y el 13,9\% al ejido Emiliano Zapata" (De Sicilia, 2000: 59). Para el caso del CIP Nayarit, previo a su implementación en 1989 se procedió a expropiar una superficie de 4.136 hectáreas a 8 ejidos, las cuales fueron administradas por el llamado Fideicomiso Bahía Banderas el cual se constituyó para desarrollar el turismo y conjuntos habitacionales en la zona del sur de Nayarit y detonarla como polo turístico (Mendoza, Hernández y Osorio, 2018: 69).

\section{San José del Cabo, Baja California Sur}

La ciudad de San José del Cabo se encuentra en el extremo sur de la península de Baja California, es la cabecera municipal de Los Cabos, en el estado de Baja California Sur (ver fig. 1). Fue fundada como misión de San José en 1730 por los padres jesuitas José de Echeverría y Nicolás Tamaral, un poco distante de la costa, cerca de un arroyo. La comunidad tomó un gran dinamismo a partir del reparto de 
tierras a civiles realizadas por el visitador José de Gálvez, además del reparto que se experimentó tras la independencia del país, consolidándose los ranchos ganaderos y agrícolas como forma de propiedad de la tierra, por lo que San José del Cabo elevó su rango a la categoría de pueblo (González, Rivas y Torres, 2013: 73). En 1857 con el reparto agrario tendiente a desarrollar los ranchos ganaderos y agrícolas, San José cobró una gran relevancia por encima de las demás localidades del territorio (La Paz, Todos Santos, San Antonio, Comondú, Mulegé y Santo Tomás) (González, Rivas y Torres, 2013a: 73-74).

Fig. 1: Ubicación de San José del Cabo, Baja California Sur

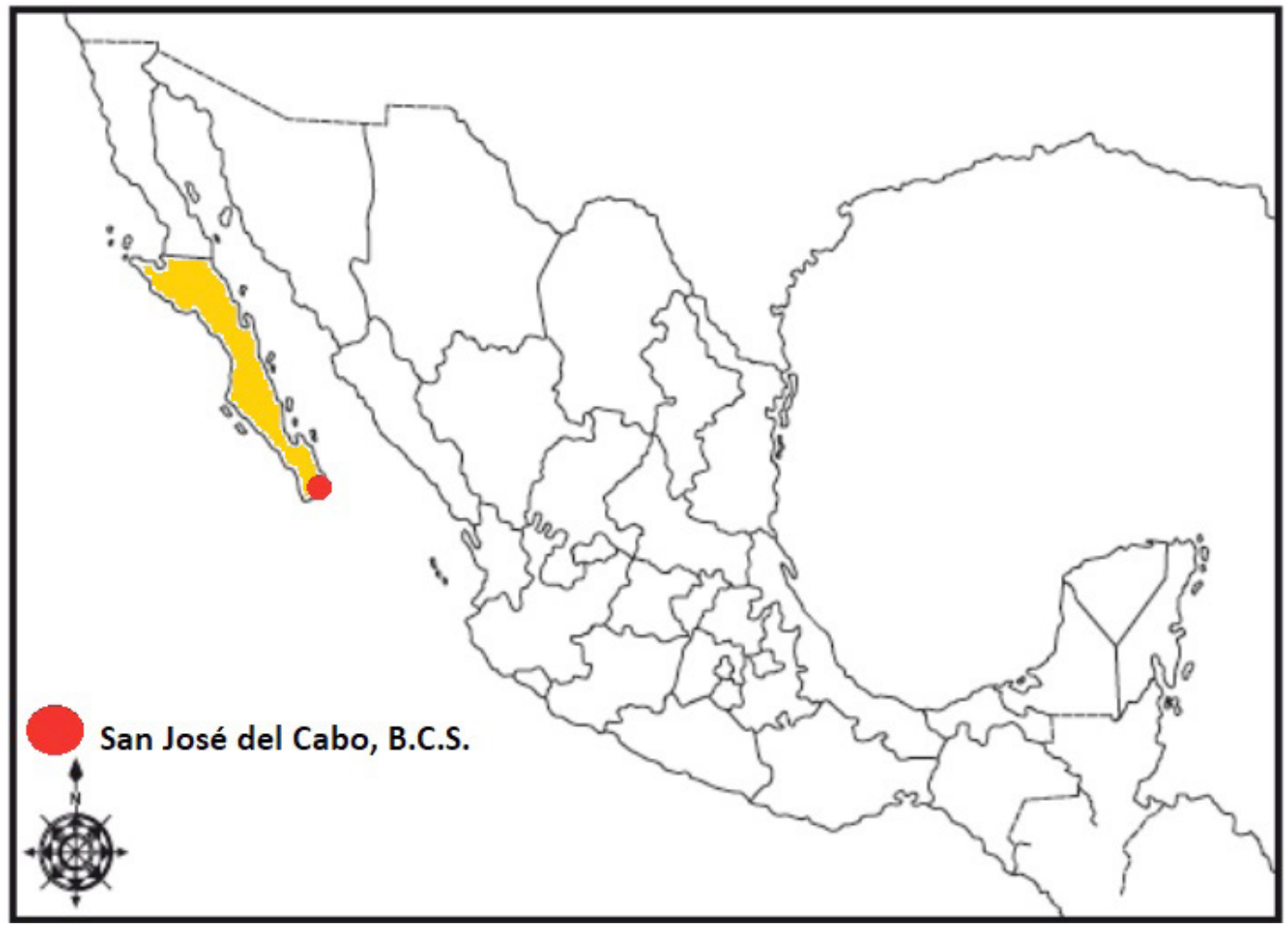

Fuente: Elaboración propia

En los años veinte del siglo pasado la agricultura cobró gran relevancia en la economía del sur del estado, las tierras que habían aperturado los jesuitas en el lejano S. XVIII retomaron su importancia con convenios con compañías extranjeras para la producción hortícola para su exportación a los Estados Unidos, sobre todo tomate, aunque también se produjo arroz, frijol, caña de azúcar (para los trapiches de la región y la generación de piloncillo) y maíz; además siguió presente la actividad ganadera para la comercialización de ganado en pie, carne desecada, queso, mantequilla y cueros para la industria peletera (Montoya, 2003: 21).

En los años cuarenta del S. XX hubo un declive en la actividades agrícola y comercial, dicha situación impactó desde el punto de vista demográfico, se presentó un descenso de población que emigró en busca de mejores perspectivas de vida y empleo, al pasar en 1940 de una población de 2.553 habitantes a 1.837 en 1950, por lo que dejó de considerarse una localidad urbana, ya que la clasificación oficial consideraba a una ciudad con un mínimo de 2.500 pobladores. Todo lo contrario, sucedió en otras localidades del territorio de Baja California Sur, como La Paz que creció un 28\% en su población al pasar de 13.654 a 17.513 habitantes (Montoya, 2003: 149)

Si bien la primera mitad del siglo XX las actividades económicas de la zona y en concreto de San José del Cabo eran de carácter agropecuario, para 1952 empezó a desarrollarse la actividad turística con 
la fundación del hotel O’Fisher cuya dueña era Carmen Fisher y que consistió en 10 habitaciones con ventilador, con una pequeña cocina. Ya antes, esta pionera del turismo había orientado sus esfuerzos en un primer negocio de comida en un pequeño restaurante que cobró relevancia entre los visitantes. Para 1956 se apertura el hotel Palmilla el cual consistió en 45 habitaciones de lujo, el cual estaba destinado para huéspedes estadounidenses; después del hotel Palmilla se inauguró el hotel Cabo San Lucas en 1959 que tuvo 88 habitaciones, aeropista para la llegada de los huéspedes, restaurante, bar, lavandería, servicio médico, además de embarcaciones para pesca deportiva (González, Rivas y Torres, 2013b: 154-156).

San José del Cabo en la actualidad forma parte de una región con gran actividad turística, está conectada con la localidad de Cabo San Lucas a través de un corredor turístico de 33 kilómetros donde están instalados hoteles de cadenas internacionales a la vera del litoral. Producto de la actividad turística su población ha crecido de manera acelerada, observándose tasas de crecimiento de $8.3 \%$ anual entre 1990 y 1995; 9,3\% entre 1995 a 2000 y 8,1\% entre 2000 a 2005 (ver tabla 1), muy por encima del promedio nacional pues entre 1990 al 2000, nuestro país experimentó una tasa anual de 1,9\%; de 2000 al 2010, de 1,4\% (Statista, 2018).

Tabla 1: Ciudades del Municipio de Los Cabos

\begin{tabular}{|l|c|c|c|c|c|c|c|}
\hline \multirow{2}{*}{ Ciudad } & \multicolumn{4}{|c|}{ Población } & \multicolumn{3}{c|}{ Tasa de crecimiento } \\
\cline { 2 - 8 } & $\mathbf{1 9 9 0}$ & $\mathbf{1 9 9 5}$ & $\mathbf{2 0 0 0}$ & $\mathbf{2 0 0 5}$ & $\begin{array}{c}\mathbf{1 9 9 0} \\
\mathbf{1 9 9 5}\end{array}$ & $\begin{array}{c}\mathbf{1 9 9 5} \\
\mathbf{2 0 0 0}\end{array}$ & $\begin{array}{c}\mathbf{2 0 0 0} \\
\mathbf{2 0 0 5}\end{array}$ \\
\hline Cabo San Lucas & 16.059 & 31.377 & 48.143 & 87.876 & 12.6 & 10.5 & 11.2 \\
\hline San José del Cabo & 16.531 & 26.011 & 38.080 & 59.325 & 8.3 & 9.3 & 8.1 \\
\hline
\end{tabular}

Fuente: Elaboración propia con datos de CONAPO. Sistema Urbano Nacional: Población y tasas de crecimiento, 1990-2005.

\subsection{El ejido de San José del Cabo}

La dotación al ejido San José del Cabo se materializó la Resolución Presidencial aprobada el 4 de enero de 1923 y publicado en el Diario Oficial de la Federación (DOF) el 2 de marzo de 1923 (DOF, 1923), beneficiándose a 272 personas con la cantidad de 12 mil hectáreas, sin embargo, la ejecución de dicha resolución presidencial no se dio sino hasta el 11 de julio de 1946. Para el 28 de marzo se presentó la primera y única ampliación del ejido con Resolución Presidencial con fecha del 19 de febrero de 1974 y publicado en el DOF el 28 de marzo de 1974 (DOF, 1974b) y con la ejecución de la Resolución Presidencial el 18 de abril de 1974 (ver Tabla 2).

Tabla 2: Dotación y ampliación al ejido San José del Cabo

\begin{tabular}{|l|l|l|l|l|l|}
\hline Acción & $\begin{array}{l}\text { Publicación } \\
\text { DOF }\end{array}$ & $\begin{array}{l}\text { Resolución } \\
\text { Presidencial }\end{array}$ & $\begin{array}{l}\text { Fecha } \\
\text { Ejecución }\end{array}$ & $\begin{array}{l}\text { Superficie } \\
\text { Ejecutada } \\
\text { (has) }\end{array}$ & Beneficiarios \\
\hline Dotación & $02-03-1923$ & $04-01-1923$ & $11-07-1946$ & 12.000 .00 & 272 \\
\hline Ampliación & $28-03-1974$ & $19-02-1974$ & $18-04-1974$ & 1.431 .00 & $-\cdots-$ \\
\hline
\end{tabular}

Fuente: Elaboración propia con base a daros del Registro Agrario Nacional.

\subsection{Ejido San José del Cabo y su aportación al CIP-Los Cabos}

La década de los setenta del siglo pasado presenció el inicio de un cambio en la política del Estado mexicano en materia turística, pues se planteó la creación e impulso de nuevos destinos turísticos de Sol y Playa en lugares remotos y con primacía en actividades agropecuarias, con la finalidad de atraer al turismo internacional de altos ingresos (López López, 2001; Dávila López, 2015). Estos sitios fueron escogidos, entre otras cosas, por su gran belleza, así como por la disponibilidad de tierra barata. Este fue el caso en San José del Cabo y Cabo San Lucas, en la península de Baja California, que más tarde serían unidos por un corredor turístico (el CIP-Los Cabos), donde se instalaron cadenas hoteleras de 
reconocida fama internacional. De acuerdo con FONATUR, en 1974 el gobierno federal, para ampliar las posibilidades turísticas buscó nuevos espacios para desarrollar destinos de esparcimiento litoral; para ello realizó estudios preliminares, y resultaron ganadores San José del Cabo y Loreto en el estado de Baja California Sur, ya que contaban con pueblos aledaños que poseían cierta infraestructura y recursos humanos, además de sus bellezas naturales y que podían impulsar centros de diversión y esparcimiento alejados de las grandes urbes .

Fue a fines del sexenio de Gustavo Díaz Ordaz, que empezó a visualizarse el proyecto turístico del gobierno federal en San José del Cabo, cuando la península de Baja California Sur fue contemplada dentro del Plan General de Desarrollos Turísticos, el cual tenía como objetivo de ampliar los destinos de Sol y Playa del país (Moya Palencia, 1982: 17).

En el caso concreto de Los Cabos, la inversión se destinó en la ciudad de San José del Cabo en energía eléctrica, telecomunicaciones, carreteras, instalaciones recreativas y saneamiento ambiental; mientras que, en la zona turística adyacente, se invirtió en la construcción de un hotel de 250 habitaciones y en la mejora del aeropuerto local (World Bank, 1974).

Más adelante, en 1974, el gobierno federal emitió varios decretos con la finalidad de expropiar extensiones de terrenos ejidales para impulsar el desarrollo turístico de Baja California Sur. Para ello, el 25 de julio de 1978, se firmó un contrato en el llamado Fideicomiso San José de Cabo, donde participaron organismos como FONATUR y la CORETT, con el objetivo de regularizar y titular los terrenos que serían ofertados a particulares en el caso de lotes residenciales, para la edificación de condominios y hoteles (World Bank, 1974).

Fig. 2: Plano de la ciudad previo al CIP

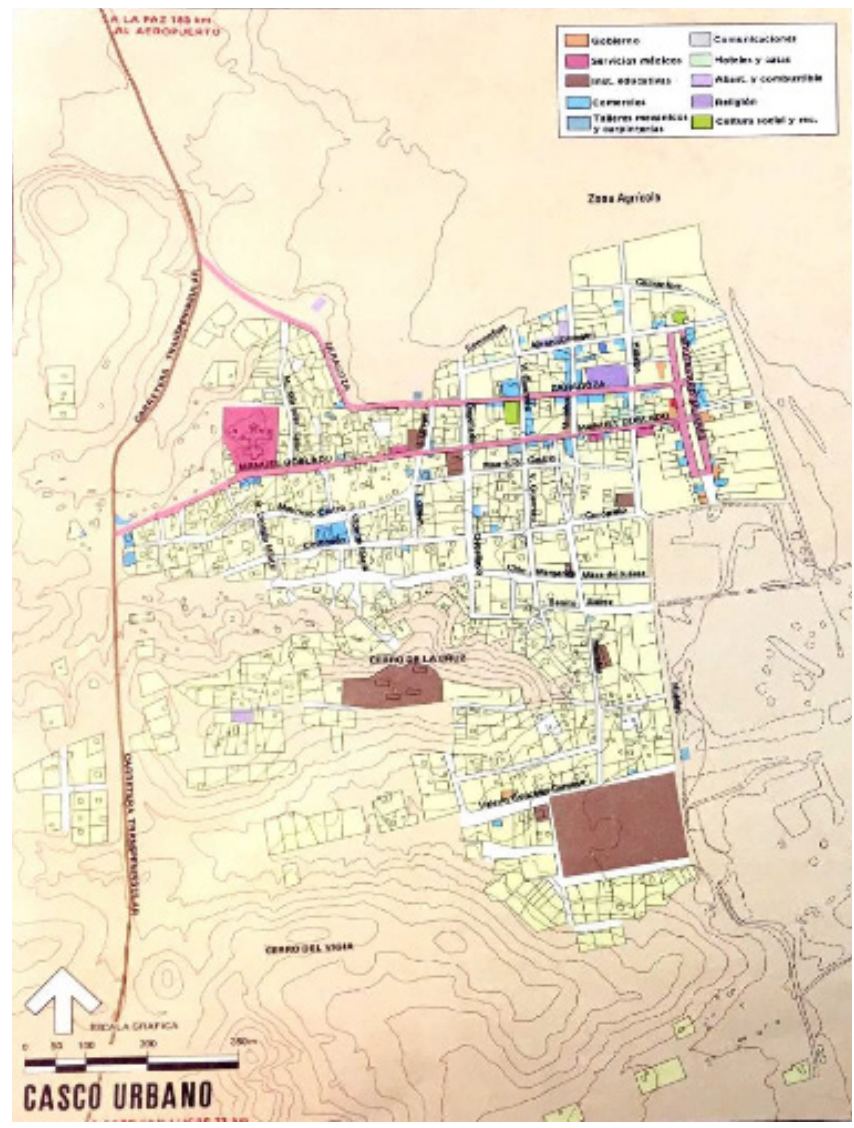

Fuente: Moya Palencia (1982). 
Fig. 3: Proyecto del CIP y su equipamiento

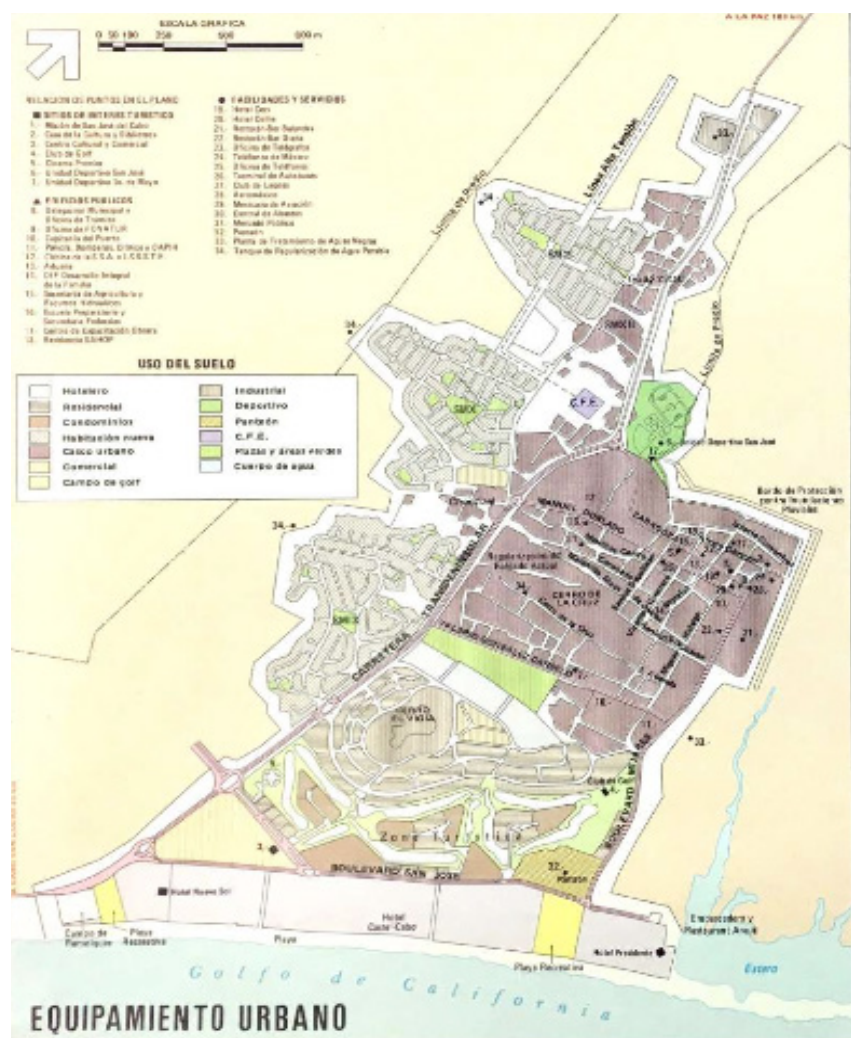

Fuente: Moya Palencia (1982).

El proyecto para San José del Cabo, Baja California Sur, contemplaba para su desarrollo 1.953 hectáreas en el municipio de La Paz, los cuales en su mayoría pertenecían al ejido San José. El Plan Maestro para el CIP Los Cabos, incluía zonas hoteleras, condominios de lujo, lotes residenciales con posición y vistas privilegiadas, playas recreativas de gran belleza, campo de golf, remodelación y equipamiento urbano. Dicho proyecto se dividió en dos etapas, una para terminarse en 1990 y la segunda para concluirse diez años después.

Para el proyecto fueron asignadas 1.795 hectáreas, más una zona federal que circundaba al estero de San José, todo ello arrojó una superficie de 1.953 hectáreas, lugar destinado para su desarrollo como centro turístico. Dicho predio corre de manera paralela a ambos lados de la carretera transpeninsular, con una longitud de $6.5 \mathrm{~km}$. aproximadamente y con un ancho de $1.5 \mathrm{~km}$. en promedio, haciéndose más ancho hacia el sur, colindaba además con la costa de la zona federal marítimo terrestre y con una longitud de playa de nueve kilómetros (Word Bank, 1974; FONATUR, 2006).

Algunos aspectos que consideró FONATUR para la realización del CIP Los Cabos, fueron, en primer lugar, la existencia de una zona urbana. En este caso el poblado de San José del Cabo, siendo este el más importante de una serie de asentamientos establecidos a lo largo de la carretera transpeninsular en una distancia de 12 kilómetros aproximados, en segundo término, cerca del futuro centro, en el extremo sur de la península, se perfilaba un corredor turístico entre San José del Cabo y Cabo San Lucas pues la característica principal de la tierra existente era que podía comprarse a sus legítimos dueños o enajenarse para bien público, hecho que posibilitaba el desarrollo futuro del turismo en la zona como sucedió con el fundo legal josefino que poseía 12 mil hectáreas, de las cuales se expropiaron 1500 hectáreas para el nuevo CIP (Word Bank, 1974).

Sin duda, el turismo ha tenido efectos multiplicadores en la economía, con la llegada de empresas constructoras, compañías inmobiliarias y empresas comerciales, además de una gran población inmigrante 
en busca de mejores oportunidades de trabajo, la cual se afincó de manera definitiva (Vázquez, 2012). Por otra parte, se generó una gran presión sobre los recursos naturales, como el suelo, el agua y las playas, que constituyen un elemento primordial del espacio turístico. La creación del CIP-Los Cabos por el FONATUR se dio a partir de la emisión de un decreto por parte de la Federación que tuvo como objetivo la expropiación de terrenos del ejido San José para construir la infraestructura del naciente destino turístico.

\subsection{Expansión urbana de la ciudad de San José del Cabo}

De un crecimiento lento que experimentó la localidad desde su fundación, San José empezó a experimentar un crecimiento acelerado tanto de su población, como de su mancha urbana, sobre todo de 1993 a la actualidad, por lo que los rezagos urbanos y la presión social por introducir los servicios básicos fue la constante (ver fig. 3).

La localidad de San José del Cabo, hasta 1980 tuvo un crecimiento moderado, el cual consistía en el viejo casco urbano, que se había constituido desde su fundación con una expansión lenta, se le suman las colonias 5 de febrero, 8 de octubre, parte de la Primero de Mayo, y parte de Chula Vista; además de una serie de asentamientos a lo largo de la transpeninsular que conforma lo que se le conoce como la ciudad lineal, como una sección de Rosarito, un sector de Guaymitas, parte de Santa Rosa, la parte aledaña a la transpeninsular de El Zacatal, las comunidades de San José Viejo, San Bernabé y las Veredas.

Es en el periodo de 1980 a 1993, cuando la ciudad empieza a experimentar un crecimiento acelerado producto de la actividad turística que detonó la creación del CIP-Los Cabos, no sólo por la expansión del área desarrollada por el polígono del proyecto de Fonatur, sino por la cantidad de empleos producto de la industria de la construcción y los puestos de trabajos asociados al turismo que creció de manera importante por las políticas públicas del sector en el municipio. Se construyó y se urbanizó el polígono del CIP y la zona turística aledaña, además crecieron los asentamientos ubicados en la llamada ciudad lineal, dándose un mayor crecimiento de los sectores de Mauricio Castro, Chula Vista, además del surgimiento de otras colonias como Jesús Castro Agúndez.

\section{Fig. 3: Crecimiento histórico de San José del Cabo, Baja California Sur}

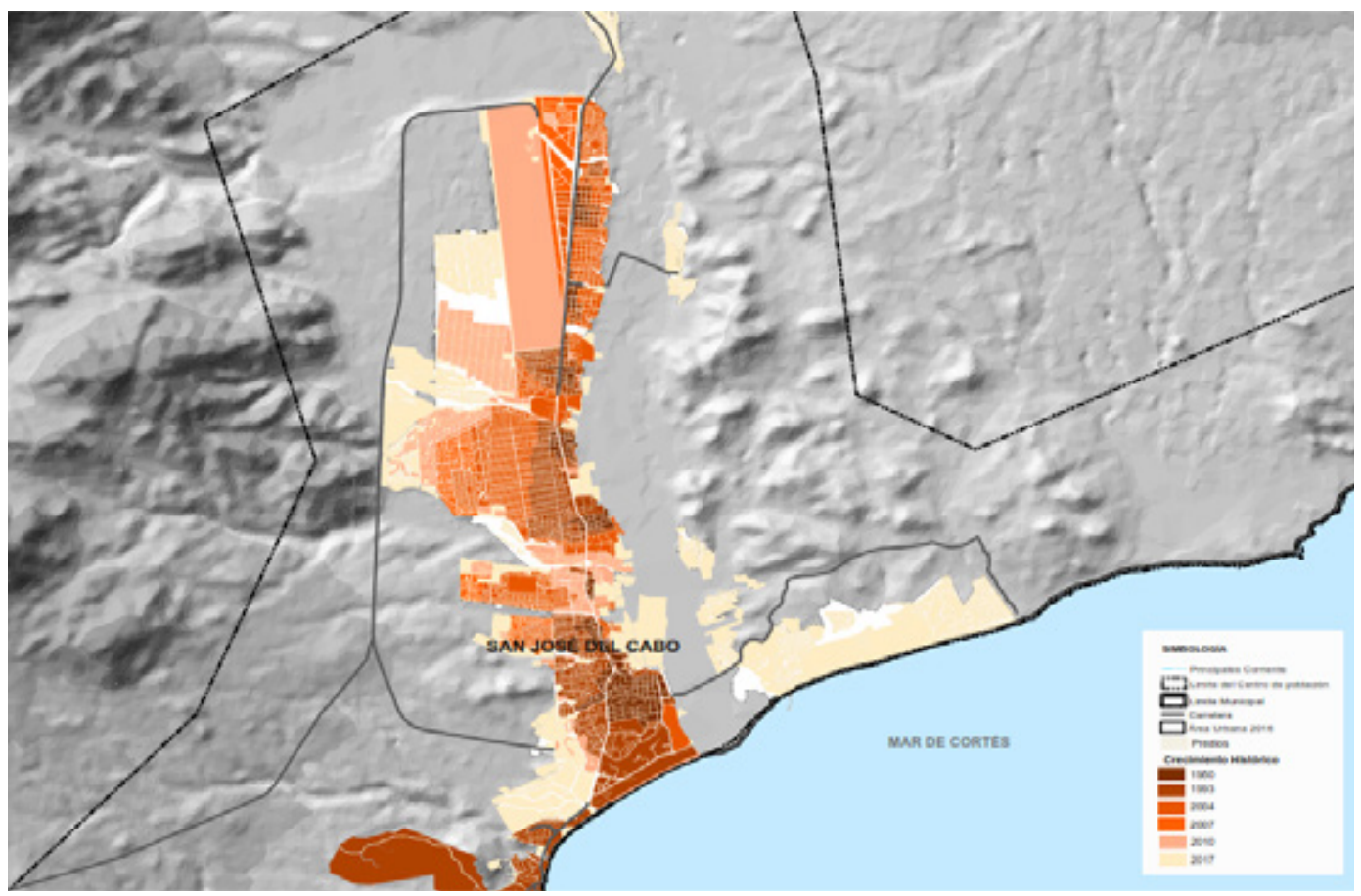

Fuente: IMPLAN-Los Cabos, 2013. 
El crecimiento exponencial de la población, se expresó en términos de la mancha urbana. En el periodo entre 1993 a 2007, el crecimiento en mayor medida hacia el norte de la ciudad, aledaño a la carretera transpeninsular, surgiendo asentamientos como la colonia Luis Dolando Colosio, Fracc. Colinas San José, Colinas Plus, Monterreal Residencial primera etapa, Lomas de Guaymitas, ampliación de las colonias Santa Rosa, Zacatal, surgimiento de la colonia Vista Hermosa. En el último periodo comprendido entre 2007 a 2017, la tendencia fue robustecer la mancha urbana de la ciudad lineal. Surgieron asentamientos como Pablo L. Martínez, Monterreal segunda etapa, Ampliación Zacatal, La Ballena (producto de una invasión y en proceso de regularización).

\subsection{Ejido San José del Cabo y su aportación a la expansión de la ciudad}

Derivado de la concreción del CIP-Los Cabos, se dio la primera expropiación y a partir de ahí se presentaron una serie de afectaciones al núcleo agrario con el propósito de regularizar asentamientos humanos que se instalaron de manera ilegal en el polígono del ejido, además de introducción de infraestructura de la Comisión Federal de Electricidad (CFE), de comunicaciones por parte de la Secretaría de Comunicaciones y Transportes (SCT) y la Secretaría de Asentamientos Humanos y Obras Públicas (SAHOP) (Ver tabla 3). Dichas expropiaciones se dieron antes y después de las reformas al artículo 27 constitucional que permitieron comercializar las tierras de propiedad social (ejidal y comunal) para destinos distintos al agropecuario, entre ellos el urbano.

Tabla 3: Expropiaciones al ejido San José del Cabo con fines de regularización

\begin{tabular}{|l|l|l|l|l|l|}
\hline Acción & $\begin{array}{l}\text { Publicación } \\
\text { DOF }\end{array}$ & $\begin{array}{l}\text { Resolución } \\
\text { presidencial }\end{array}$ & $\begin{array}{l}\text { Fecha } \\
\text { ejecución }\end{array}$ & $\begin{array}{l}\text { Superficie } \\
\text { ejecutada }\end{array}$ & Promovente \\
\hline EXPROPIACIÓN & $31-08-1976$ & $30-08-1976$ & $09-09-1977$ & 1373.025000 & CORETT \\
\hline EXPROPIACIÓN & $18-10-1976$ & $28-06-1976$ & $17-12-1990$ & 1.000000 & CFE \\
\hline EXPROPIACION & $13-03-1986$ & $20-01-1986$ & $30-11-1987$ & 0.974900 & SCT \\
\hline EXPROPIACION & $22-10-1990$ & $04-10-1990$ & $07-12-1990$ & 155.366000 & CORETT \\
\hline EXPROPIACIÓN & $25-10-1974$ & $04-10-1974$ & $28-04-1978$ & 295.000000 & BANOPSA \\
\hline EXPROPIACIÓN & $03-07-1980$ & $23-04-1980$ & $28-07-1985$ & 497.537743 & SAHOP \\
\hline EXPROPIACIÓN & $19-02-1992$ & $03-01-1992$ & $26-07-1992$ & 314.620000 & SEDUE \\
\hline EXPROPIACIÓN & $01-09-1994$ & $26-08-1994$ & $21-10-1998$ & 1.392300 & SCT \\
\hline
\end{tabular}

Fuente: Elaboración propia en base a datos del Registro Agrario Nacional.

\subsection{Expropiaciones al ejido San José del Cabo para fines urbanos e infraestructura}

Después de expropiada una superficie importante para la materialización del polo turístico impulsado por FONATUR, el 31 de agosto de 1976 se publicó en el DOF una resolución presidencial de expropiación de 155.9355 hectáreas, solicitada por la Comisión Reguladora de la Tenencia de la Tierra (CORETT), para destinarlas a su lotificación y titulación legal a favor de sus ocupantes, mediante su venta y la constitución de una reserva territorial que sirviera en el futuro para satisfacer las demandas del crecimiento regular de la localidad. Dicha resolución presidencial fue ejecutada el 9 de septiembre de 1977, pero sólo por 1373.025000 hectáreas (DOF, 1976a).

La tercera expropiación se publicó el 18 de octubre de 1976 en el DOF, donde la CFE solicitaba la expropiación de $10.000 \mathrm{~m} 2$ de terrenos para la construcción de una subestación eléctrica con el objeto de abastecer la demanda de fluido eléctrico que requería la zona, la ejecución dio dicha resolución presidencial fue el 17 de diciembre de 1990 (DOF, 1976b). El Cuarto acto expropiatorio, el cual fue promovido por la SCT y publicado el 13 de marzo de 1986 en el DOF. La superficie solicitada de poco menos de una hectárea era para la edificación de un campamento de conservación, la dependencia federal se hizo cargo de la indemnización correspondiente (DOF, 1986).

La quinta afectación al núcleo agrario fue publicada el 22 de octubre de 1990, siendo promovida por la CORETT donde solicitó la expropiación de 136.1100 hectáreas para destinarlos a su regularización y titulación legal a favor de sus ocupantes mediante su venta (DOF, 1990). Dicha expropiación fue ejecutada el 7 de diciembre de 1990. La sexta expiación con fines de utilidad pública fue promovida por 
la Secretaría de Asentamientos Humanos y Obras Públicas (SAHOP) y publicada el 3 de julio de 1980 y ejecutada el 28 de julio de 1985, siendo destinada la superficie fue de 497.537743, la cual se destinó para la construcción del Aeropuerto Internacional de Los Cabos (DOF, 1980).

La séptima afectación al núcleo ejidal fue promovida por la Secretaría de Desarrollo Urbano y Ecología (SEDUE) y publicada en el DOF el 19 de febrero de 1992, la cual solicitaba la expropiación de 314.620000 para destinarlas a la constitución de reservas territoriales para el futuro crecimiento de la ciudad. La octava y última expropiación, fue a solicitud de la SCT y publicado en el DOF el 1 de septiembre de 1994, la cual solicitó una superficie de 1.392300 para el derecho de vía para la construcción del entronque aeropuerto San José del Cabo de la carretera transpeninsular tramo San José del Cabo-Cabo San Lucas (DOF, 1994).

\subsection{Invasiones recientes al núcleo agrario}

San José del Cabo sigue siendo foco de atracción para inmigrantes en la búsqueda de empleo, a la par que su población sigue creciendo y demandando más suelo urbanizable, por lo que el fenómeno de invasiones tanto en terrenos ejidales como en zonas de arroyos y de carácter federal sigue estando vigentes. En el presente y el futuro, el ejido seguirá siendo el principal agente que proporcionará suelo urbanizable, pues la ciudad se encuentra en medio del polígono ejidal (Implan-Los Cabos, 2013) (ver fig. 4).

Fig. 4: Tenencia de la Tierra en San José del Cabo

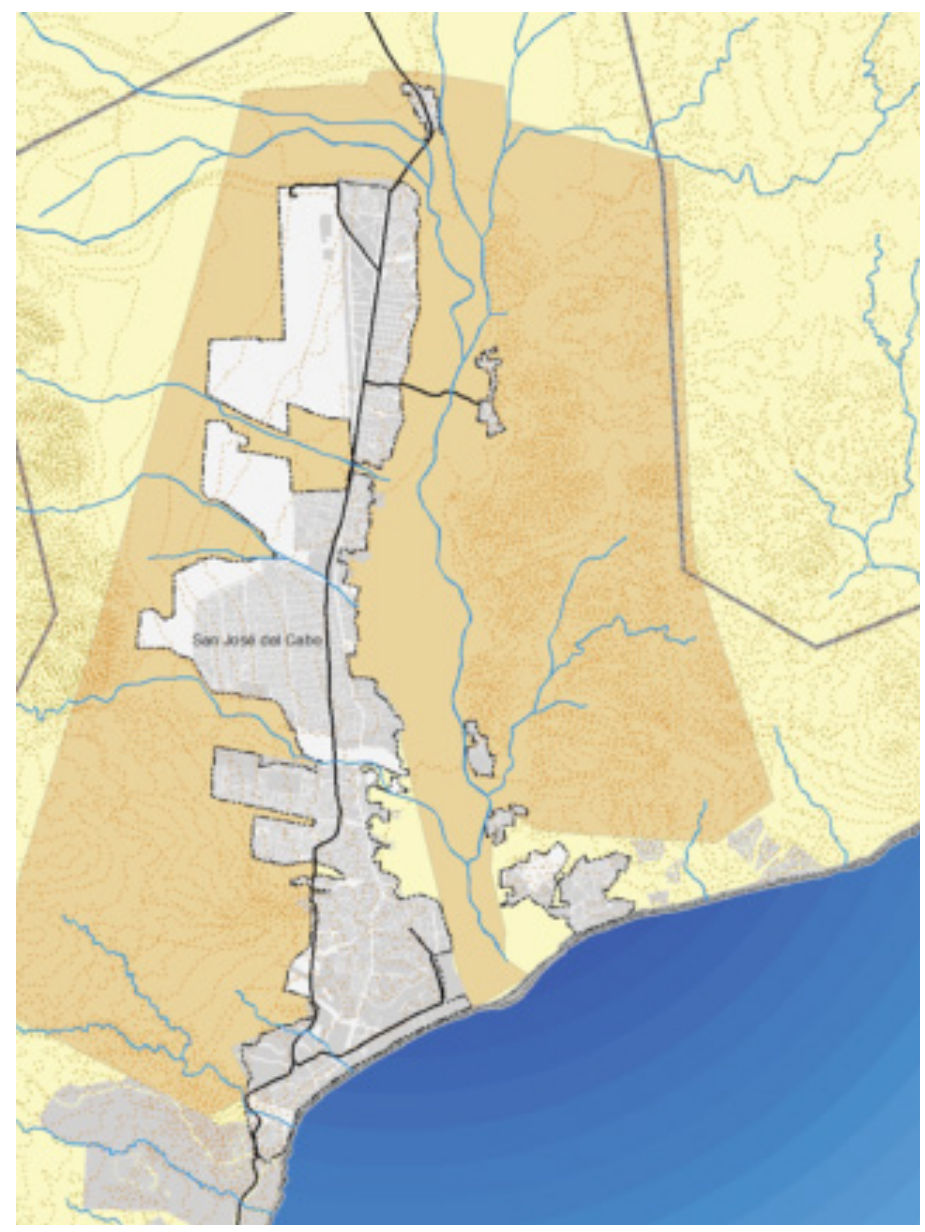

Fuente: IMPLAN-Los Cabos (2013). 
En los últimos años derivado de un resurgimiento de las inversiones en nuevos hoteles y edificaciones ligadas a la actividad turística e inmobiliaria, se ha dado un alto crecimiento poblacional en el municipio de Los Cabos, aumentando así el riesgo que tienen los núcleos agrarios de sufrir invasiones, por lo que el ejido San José del Cabo anunció la intención de comercializar 600 hectáreas a familias de escasos recursos económicos que carezcan de vivienda, además para reubicar a familias que están en zonas de riesgo de acuerdo con declaraciones del director general de Planeación y Desarrollo Urbano del Ayuntamiento de Los Cabos (BCS Noticias, 2016).

No sólo el ejido ha contribuido a resolver el problema de falta de suelo, sino que también ha proporcionado suelo para la construcción del nuevo libramiento Cabo San Lucas-San José del Cabo, suelo que hasta el momento no ha sido pagado por lo que se han manifestado ante las autoridades de la SCT en el estado, pues autoridades del ejido afirman les adeudan por ese concepto cerca de 21 millones de pesos a 272 ejidatarios los cuales debieron de ser indemnizados en el año 2010 (Gaxiola, 2016).

En cuanto a las invasiones, el ejido en la actualidad tiene invadidas 650 hectáreas. Uno de los casos más emblemáticos de esta problemática fue la invasión del predio ejidal de La Ballena, el cual se está regularizando, hay 4.067 lotes ocupados que tienen contratos de arrendamiento, que no significa que estén enajenados, sólo eso se llevará a cabo cuando todos los lotes estén en registro público de propiedad, éstos estarán a disposición para celebrar un contrato de compra venta. En La Ballena hay seis mil lotes, además de suficiente reserva para el crecimiento en un futuro del aeropuerto internacional (Cabovisión, 2017).

Autoridades municipales en diálogo constante con los representantes ejidales buscan la obtención de 100 hectáreas para reservas territoriales de la ciudad, las cuales serán utilizadas para la reubicación de familias, actualmente asentadas en zonas de riesgo, dicha superficie se encuentra en el predio La Ballena (Cabo Mil, 2018).

\section{Conclusiones}

Las ciudades mexicanas se encontraron con un obstáculo en su continuidad para su expansión en la existencia de distintas formas de propiedad, entre ellas la de propiedad social (ejidal y comunal), las cuales no se podían enajenar y destinarla para fines distintos de su naturaleza jurídica, lo que generó tensiones con las necesidades de reservas territoriales de las localidades urbanas. De la misma forma, la política turística del Estado mexicano en los años setenta significó el desarrollo de zonas en la periferia territorial mexicana que con sus características de prístina belleza, pero con alta presencia de núcleos agrarios cuyas tierras no eran compatibles con la actividad turística, por lo que los ejidos fueron objeto de expropiaciones con fines de utilidad pública en sendos decretos presidenciales para la obtención de los polígonos necesarios para la concreción de los llamados CIP por parte de FONATUR.

La aportación de los ejidos a la creación del CIP fue un primer paso que tuvo consecuencias en el futuro para los ejidos, donde la ola de inmigración propiciada por esa actividad turística significó la demanda de suelo urbanizable que los salarios otorgados por las empresas hoteleras y de servicios eran insuficientes para accesar al suelo de manera formal y legal, por lo que las invasiones a los núcleos agrarios fueron una válvula de escape ante un modelo de desarrollo turístico con gran especulación inmobiliario que tenía como sello característico la segregación y polarización espacial.

En el caso del CIP Los Cabos, significó el despojo al ejido de las tierras para la materialización del polo de desarrollo turístico y el inicio de una serie de expropiaciones para legalizar los asentamientos ilegales que se aposentaron en tierras del ejido ante un crecimiento poblacional explosivo, resultado de la dinámica de la economía turística y el que San José del Cabo se convirtió en un foco de atracción para gente de todas las partes del país que buscaban mejores condiciones laborales y de vida.

Si bien, las reformas al artículo 27 constitucional decretadas en 1992 contribuyeron a dar certeza jurídica para los sujetos agrarias y poder comercializar sus tierras para fines urbanos, las condiciones de marginación, pobreza y los altos costos de vivienda y suelo en el mercado formal han originado que sigan existiendo asentamientos irregulares en la ciudad, por lo tanto el ejido San José del Cabo tendrá que establecer estrategias de comercialización a sectores vulnerables que signifique un beneficio mutuo tanto para ejidatarios como para destinatarios de lotes urbanizables. Derivado que la ciudad está rodeada de tierras del ejido, en el futuro el núcleo ejidal será el único aportador de tierra para vivienda, por lo que urge el establecimiento de convenios y estrategias entre las autoridades municipales y ejidales para asegurar reservas territoriales que genere certidumbre y armonización del crecimiento físico de la ciudad. 


\section{Bibliografía}

Aldape, G. 2010. La configuración del espacio turístico en Cancún, Quintana Roo, México, Tesis doctoral, Universidad Politécnica de Cataluña, Barcelona, España.

Amer, J. 2011. Políticas públicas y vulnerabilidad social en destinos turísticos maduros. El estudio de caso del Consorcio de la Platja de Palma. Gran Tour, 3, 31-50

BCS Noticas 2016, 10 de mayo. Ejido San José del Cabo venderá 600 hectáreas; quieren frenar más invasiones. BCS Noticias. Disponible en: http://www.bcsnoticias.mx/ejido-san-jose-del-cabo-vendera-600-hectareas-quieren-frenar-mas-invasiones/

Bojórquez Luque, J. 2011. Importancia de la tierra de propiedad social en la expansión de las ciudades en México. Ra Ximhai, 7(2), 297-311.

Bojórquez Luque, J. 2013. Expansión urbana en áreas ejidales en el marco de las reformas al artículo 27 constitucional y el desarrollo turístico en Cabo San Lucas, Baja California Sur. Tesis de Maestría, Universidad Autónoma de Baja California Sur, La Paz, México.

Bojórquez Luque, J. 2014. Evolución y planeación urbana en la ciudad turística de Cabo San Lucas, Baja California Sur (México). Pasos, 12(2), 341-356.

Bojórquez Luque, J.; Ángeles, M. 2014. Expansión turística y acumulación por desposesión: el caso de Cabo San Lucas, Baja California Sur (México). Cuadernos de Geografía, 23(2), 179-202.

Cabo Mil 2018, 30 de mayo. A punto de cerrarse negociación de 100 hectáreas para reubicar familias en zonas de riesgo en SJC: Luis Alberto González. Cabo Mil, 30 de mayo. Recuperado de: http:// cabomil.com.mx/index.php/rss/1951-a-punto-de-cerrarse-negociacion-de-100-hectareas-para-reubicar-familias-en-zonas-de-riesgo-en-sjc-luis-alberto-gonzalez

Cabovisión 2017, 19 de marzo. 650 hectáreas de Ejido SJC están invadidas. Cabovisión. Disponible en: http://cabovision.tv/index.php/noticias-hidden/26971-650-hectareas-de-ejido-sjc-estan-invadidas

Castro, U. 2007. El turismo como política central de desarrollo y sus repercusiones en el ámbito local: algunas consideraciones referentes al desarrollo de enclaves turísticos en México. Turydes, 1 (1). Disponible en: http://www.eumed.net/rev/turydes/01/index.htm

Dávila, A. 2015. Centros Integralmente Planeados (CIP) en México. Quaderns de Recerca en Urbanisme, 5/6. Disponible en: http://www.raco.cat/index.php/QRU/article/view/311319

De Sicilia, R. 2000. El corredor turístico Loreto-Nopoló-Puerto Escondido, Baja California Sur, en el contexto de los Centros Integralmente Planeados. Cuadernos de Turismo, 5, 53-68.

Del Castillo, A. 2014, 18 de enero. CIP, los negocios de un exgobernador. Milenio. Disponible en: http:// www.milenio.com/estados/cip-los-negocios-de-un-exgobernador

Diario Oficial de la Federación (DOF) 1923, 2 de marzo. Resolución en el expediente de restitución de ejidos promovidos por el pueblo de San José del Cabo, Distrito Sur del Territorio de Baja California. Disponible en: https://www.dof.gob.mx/nota_to_imagen_fs.php?codnota $=4505736 \&$ fecha=02/03/192 3\&cod_diario=191714

DOF 1973a, 1 de febrero. Decreto que expropia por causa de utilidad pública, una superficie de 813-91-96 hectáreas del ejido Agua de Correa, Municipio de José Azueta, Gro., en favor del Banco Nacional de Obras Nacional de Obras y Servicios Públicos, S. A. Disponible en: https://www.dof.gob.mx/ nota_to_imagen_fs.php?codnota $=4601315 \&$ fecha $=01 / 02 / 1973 \&$ cod_diario $=197549$

DOF 1973b, 1 de febrero. Decreto que expropia por causa de utilidad pública, una superficie de 206-40-00 hectáreas del ejido El Rincón, Municipio de José Azueta, Gro., en favor del Banco Nacional de Obras y Servicios Públicos, S. A. Disponible en: https://www.dof.gob.mx/nota_to_imagen_fs.php?codnota= $4601341 \&$ fecha $=01 / 02 / 1973 \&$ cod_diario $=197549$

DOF 1973c, 1 de febrero. Decreto que expropia por causa de utilidad pública, una superficie de 480-00-00 hectáreas del ejido Zihuatanejo, Municipio de José Azueta, Gro., en favor del Banco Nacional de Obras y Servicios Públicos, S. A. Disponible en: https://www.dof.gob.mx/nota_to_imagen_fs.php?co dnota $=4601413 \&$ fecha $=01 / 02 / 1973 \&$ cod_diario $=197549$

DOF 1974a, 28 de enero. Ley de Fomento al Turismo. Disponible en: https://www.dof.gob.mx/nota_to_imagen_fs.php?codnota $=4657902 \&$ fecha $=28 / 01 / 1974 \&$ cod_diario $=200563$

DOF 1974b, 28 de marzo. Resolución sobre ampliación del ejido solicitada por vecinos del poblado denominado San José del Cabo, municipio de La Paz, Territorio de Baja California. Disponible en: https:// www.dof.gob.mx/nota_to_imagen_fs.php?codnota $=4666811 \&$ fecha $=28 / 03 / 1974 \&$ cod_diario $=201035$

DOF 1976a, 31 de agosto. Decreto por el que se expropia por causa de utilidad pública una superficie del terreno al ejido San José del Cabo, Municipio de La Paz, B.C.S. Disponible en: https://www.dof. gob.mx/nota_to_imagen_fs.php?codnota $=4850539 \&$ fecha $=31 / 08 / 1976 \&$ cod_diario $=208561$ 
DOF 1976b, 18 de octubre. Decreto que expropia por causa de utilidad pública una superficie de terreno al ejido San José del Cabo, Municipio de La Paz, BCS. Disponible en: https://www.dof.gob.mx/ nota_to_imagen_fs.php?codnota $=4852429 \&$ fecha $=18 / 10 / 1976 \&$ cod_diario $=208622$

DOF 1980, 3 de julio. Decreto por el que se expropia por causa de utilidad pública una superficie de 497-53-77.43 hectáreas a favor de la Secretaría de Asentamientos Humanos y Obras Públicas ubicada en el ejido denominado San José del Cabo, perteneciente al municipio de La Paz, BCS. Disponible en: https://www.dof.gob.mx/nota_to_imagen_fs.php?cod_diario=208695\&pagina=6\&seccion=2

DOF 1984, 29 de mayo. Decreto que, por causa de utilidad pública, se expropia una superficie de 20,975-01-65 has, a favor de la Secretaría de Desarrollo Urbano y Ecología, ubicada en el ejido santa María Huatulco, perteneciente al mismo nombre, Oaxaca (Reg. -4469). Disponible en: https://www.dof.gob. $\mathrm{mx} /$ nota_to_imagen_fs.php?codnota $=4670645 \& \mathrm{fecha}=29 / 05 / 1984 \&$ cod_diario $=201236$

DOF 1986, 13 de marzo. Decreto por el que se expropian terrenos ejidales del poblado denominado San José del Cabo, ubicado en el Municipio de La Paz, BCS. Disponible en: https://www.dof.gob.mx/ nota_to_imagen_fs.php?cod_diario $=206137 \&$ pagina $=29 \&$ seccion $=0$

DOF 1990, 22 de octubre. Decreto por el que se expropia por causa de utilidad pública una superficie de usos colectivos de agostadero del ejido San José del Cabo, Municipio de Los Cabo, antes de La Paz, BCS. Disponible en: https://www.dof.gob.mx/nota_to_imagen_fs.php?codnota $=4684710 \& f e c h a$ $=22 / 10 / 1990 \&$ cod_diario $=201849$

DOF 1994, 1 de septiembre. Decreto por el que se expropia por causa de utilidad pública una superficie de 1-39-23 hectáreas de agostadero de uso común, de terrenos ejidales del poblado San José del Cabo, municipio de Los Cabos, BCS. Disponible en: https://www.dof.gob.mx/nota_to_imagen_fs.php?codno ta $=4734170 \&$ fecha $=01 / 09 / 1994 \&$ cod_diario $=203994$

Fondo Nacional de Fomento al Turismo (FONATUR) 2006a. Programa Maestro de Desarrollo Portuario 2006-2015. Administración Portuaria Integral Cabo San Lucas. Cabo San Lucas, Baja California Sur: Administración Portuaria Integral Cabo San Lucas-Fondo Nacional del Fomento al Turismo-Baja Mantenimiento y Operación. Disponible en: http://www.sct.gob.mx/fileadmin/CGPMM/PNDP2008/ doc/pms/pmdp/csl.pdf

Gallart, M. 1997. Funciones y atribuciones del Registro Agrario Nacional. Estudios Agrarios, 6. Disponible en: http://www.pa.gob.mx/publica/pa070616.htm

Gaxiola, I. 2016, 17 de junio. Ejidatarios de los cabos se manifiestan en el centro SCT; piden pago de 21 mdp. El Informante. Disponible en: http://elinformantebcs.mx/ejidatarios-los-cabos-se-manifiestan-centro-sct-piden-pago-21-mdp/

Gómez, K. 2015. ¿Quién construye el paraíso? Análisis de caso de tres espacios en la región turística de Ixtapa-Zihuatanejo. $20^{\circ}$ Encuentro Nacional sobre Desarrollo Regional en México, Cuernavaca, Morelos del 17 al 20 de noviembre de 2015, AMECIDER - CRIM, UNAM.

González, E.; Rivas, I.; Torres, L. 2013b. Historia cultural e imágenes de San José del Cabo, La Paz, Baja California Sur: Instituto Sudcaliforniano de la Cultura.

González, E.; Rivas, J. y Torres, L. 2013a. Un acercamiento al proceso de urbanización en Baja California Sur durante la época porfiriana: el caso de San José del Cabo. Tzintzun, 58, 71-98.

González, J. 2013. Problemáticas urbanas en los enclaves turísticos: turismo como estrategia para el ordenamiento urbano y territorial. Bitácora Urbano Territorial, 22, 7-10.

González, J. 2015. Políticas urbano-turísticas poscrisis. Desregulación de la práctica urbanística y tematización como estrategias para la reconversión de destinos turísticos. URBS, 5(2), 43-162.

Hernández, E. 2018. Turismo y miedo al delito-violencia. El caso de la ciudad histórica de Guanajuato (México). Estudios y Perspectivas en Turismo, 27, 805 - 830.

Inda, M. y Santamaría, A. 2015. Los centros integralmente planeados (CIPs) en México. Revista Latinoamericana de Turismología, 1(1), 36 -53.

Instituto Municipal de Planeación de Los Cabos (IMPLAN-Los Cabos) 2013. Segunda Actualización del Plan Director de Desarrollo Urbano San José del Cabo y Cabo San Lucas, BCS 2040, Los Cabos, Baja California Sur: Municipio de Los Cabos.

Jiménez, E.; Ayala, M. 2015. Los ejidos y comunidades indígenas ante la expansión de Guadalajara, 1920-2000. En Olivera, G. (Coord.), La urbanización social y privada del ejido Ensayos sobre la dualidad del desarrollo urbano en México. Cuernavaca: UNAM.

López, A. 2001. Análisis de la organización territorial del turismo de playa en México, 1970-1996: el caso de Los Cabos, BCS. Tesis doctoral, Universidad Nacional Autónoma de México, Distrito Federal, México. 
Mendoza, M.; Hernández, R.; Osorio, M. 2018. El Centro Integralmente Planeado (CIP) Litibú (Nayarit) y sus efectos en la comunidad de Higuera Blanca: paradojas, reacciones y negociaciones. Turismo y Sociedad, XXII, 65-84. Doi: https://doi.org/10.18601/01207555.n22.04

Montoya, A. 2003. Caracterización de la economía y sociedad cabeñas en la frontera del S. XXI: un enfoque histórico, Tesis de Licenciatura, Universidad Autónoma de Baja California Sur, La Paz, México.

Moya Palencia, M. (Coord.) 1982. San José del Cabo. Un desarrollo turístico de cara al Siglo XXI, México: FONATUR.

Olivera, G. 2015. La incorporación de suelo social al crecimiento urbano de Cuernavaca y sus efectos en el desarrollo urbano formal e informal del suelo y la vivienda”. En Olivera, G. (Coord.). La urbanización social y privada del ejido Ensayos sobre la dualidad del desarrollo urbano en México. Cuernavaca, Mëxico: UNAM.

Picornell, C. 1993. Los Impactos del Turismo. Papers de Turisme, 11, 83-90.

Pola, S.; Méndez, Y.; Vieyra, A. 2017. Acceso al suelo ejidal periurbano: análisis desde el capital social. Economía, Sociedad y Territorio, VII (54), 429-460. DOI: http://dx.doi.org/10.22136/est002017728

Ramírez, A. 2003. Comisión Reguladora de la Tenencia de la Tierra (CORETT). Pódium Notaria, 28, 130-133.

Rivera, I. 2011. El desarrollo urbano de la propiedad agraria. En López, S. y Fernández, J. (Coords.). Derecho Urbanístico, México: Universidad Nacional Autónoma de México.

Rodríguez, N. 2015. Efectos del crecimiento urbano en una ciudad turística de montaña San Carlos de Bariloche, Patagonia Argentina. Investigaciones Turísticas, 10, 202-230.

Romero, A.; Caballero, A.; Pérez, P. 2017. Expansión urbana y turismo en la comarca del campo de Cartagena-mar menor (Murcia). Impacto en el sellado del suelo. Cuadernos de Turismo, 39, 521-546 DOI: http://dx.doi.org/10.6018/turismo.39.290691 .

Romero, J. M.; Del Caño, S.; Romero, Y. 2014. Expansión urbana, turística y demográfica en el litoral. Y reflexión sobre la frontera Marruecos y España. En Cerezo, A.; De Pedro, L.; Medina Checa, J.M. (Coords.), Congreso Universitario Internacional de Turismo en Andalucía y Norte de Marruecos. Nuevos retos, nuevas propuestas. España: Universidad de Málaga.

Sosa, A.P.; Cazal, A. 2015. El espacio público en la ciudad de Cancún frente al proyecto turístico. URBS, 5(2) 65-80.

Statista 2018. Evolución de la tasa de crecimiento de la población en México entre 1990 y 2015. Disponible en: https://es.statista.com/estadisticas/575917/tasa-de-crecimiento-de-la-poblacion-en-mexico/

Talledos, E. 2012. La imposición de un espacio: de La Crucecita a Bahías de Huatulco. Revista Mexicana de Ciencias Políticas y Sociales, LVII (216), 119-142.

Vázquez, L. 2012. Cambios económicos en la región de Los Cabos a partir de una economía mercantil en las primeras décadas del S.XX hasta llegar a una economía turística (Tesis de maestría). La Paz, México: Universidad Autónoma de Baja California Sur. Disponible en http://biblio.uabcs.mx/tesis/ te2869.pdf

Word Bank 1974. Mexico Appraisal of the Baja California Tourism Project, 1974. Disponible en: http:// documentos.bancomundial.org/curated/es/485021468278729268/pdf/multi-page.pdf.

\section{Notas}

1 Esta institución fue creada por el Estado mexicano "orientado principalmente a la regularización de la tenencia de la tierra en asentamientos humanos irregulares en tierras de origen ejidal, comunal y propiedad federal, mediante la expropiación con el consenso de todos los involucrados, para su posterior regularización y escrituración de lotes a favor de las familias que los ocupan" (Ramírez, 2003).

2 El Registro Agrario Nacional es un "órgano administrativo desconcentrado de la Secretaría de la Reforma Agraria, responsable del control de la tenencia de la tierra y la seguridad documental derivadas de la aplicación de la propia ley. En el RAN deben inscribirse los documentos en que constan las operaciones originales y las modificaciones que sufra la propiedad de las tierras y los derechos legalmente constituidos sobre la propiedad ejidal y comunal" (Gallart, 1997). 